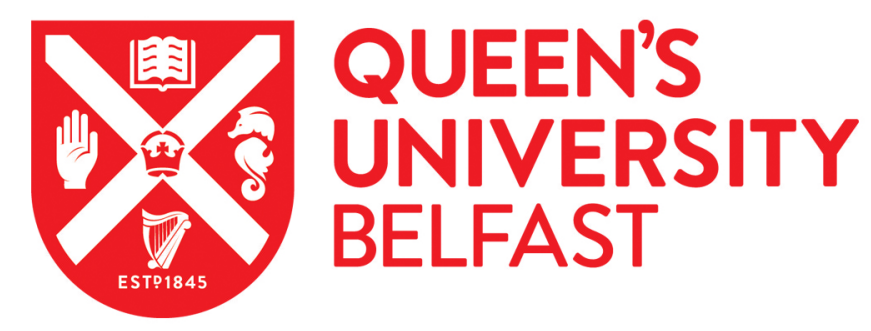

\title{
Cuts both ways: Ethnicity, poverty, and the social gradient in child welfare interventions
}

Webb, C., Bywaters, P., Scourfield, J., Davidson, G., \& Bunting, L. (2020). Cuts both ways: Ethnicity, poverty, and the social gradient in child welfare interventions. Children and Youth Services Review, 117, [105299]. https://doi.org/10.1016/j.childyouth.2020.105299

Published in:

Children and Youth Services Review

Document Version:

Peer reviewed version

Queen's University Belfast - Research Portal:

Link to publication record in Queen's University Belfast Research Portal

Publisher rights

(C) 2020 Elsevier Ltd.

This manuscript is distributed under a Creative Commons Attribution-NonCommercial-NoDerivs License

(https://creativecommons.org/licenses/by-nc-nd/4.0/), which permits distribution and reproduction for non-commercial purposes, provided the author and source are cited.

\section{General rights}

Copyright for the publications made accessible via the Queen's University Belfast Research Portal is retained by the author(s) and / or other copyright owners and it is a condition of accessing these publications that users recognise and abide by the legal requirements associated with these rights.

Take down policy

The Research Portal is Queen's institutional repository that provides access to Queen's research output. Every effort has been made to ensure that content in the Research Portal does not infringe any person's rights, or applicable UK laws. If you discover content in the Research Portal that you believe breaches copyright or violates any law, please contact openaccess@qub.ac.uk. 
Cuts both ways: ethnicity, poverty, and the social gradient in child welfare interventions

Calum Webb, the University of Sheffield*

Paul Bywaters, Huddersfield University

Jonathan Scourfield, Cardiff University

Gavin Davidson, Queen's University Belfast

Lisa Bunting, Queen's University Belfast

*Corresponding author: Department of Sociological Studies, the University of Sheffield, Sheffield, UK. S10 2TU.c.j.webb@sheffield.ac.uk

\begin{abstract}
:
This article presents the findings of a quantitative intersectional analysis of child welfare interventions within small area ethnic populations in England. Recent research has highlighted that White British children, on average, have higher rates of intervention than children from other ethnic groups in poorer neighbourhoods and lower rates in more affluent neighbourhoods. This raises the question of whether structural associations between poverty and child welfare interventions apply equally to children from all backgrounds, or whether recent research into socioeconomic child welfare inequalities is largely capturing differences between ethnic groups. We investigate this question using multilevel negative binomial regression models predicting rates of children in need, children on child protection plans, and children in State care in ethnic group populations in geographical areas with average populations of 7,200 children and adults. We find significant differences in ethnic group intervention rates, depending on levels of deprivation. Available data have significant limitations, but intersectional analysis identifies that a social gradient does not apply to, or is much smaller for, many ethnic populations and is strongest for White and Mixed Heritage populations. Socioeconomic inequalities in child protection are highly contingent on the ethnicity of the population, reflecting broader sociological literature related to race and class. This limits the generalisability of nonintersectional child welfare inequalities and introduces new avenues and imperatives for research seeking to better understand both ethnic and socioeconomic inequalities in children's social services. We consider that, beyond institutional racism, social work may need to grapple with complex forms of 'institutionalised intersectional injustice'.
\end{abstract}

Keywords: class, race, intersectionality, whiteness, child protection

\title{
Highlights:
}

- Significant ethnic inequalities in child protection, controlling for deprivation.

- The social gradient is strongest for White and Mixed Heritage populations.

- No evidence of a social gradient for Indian and Bangladeshi populations.

- Weaker social gradients for some interventions for other populations.

- Child welfare inequalities must be understood through an intersectional lens.

\section{Acknowledgements:}

The authors wish to acknowledge the support of the Nuffield Foundation which funded the work reported here (grant reference: KID 41935/03). The Nuffield Foundation is an endowed charitable trust that aims to improve social well-being in the widest sense. It funds 
research and innovation in education and social policy and also works to build capacity in education, science and social science research. The views expressed are those of the authors and not necessarily those of the Foundation. More information is available at www.nuffieldfoundation.org.

We are grateful to Professor Brid Featherstone, Professor Kate Morris, Dr. Will Mason, and Dr. Claire McCartan for their comments on early drafts of this articles and for their support during the research process. 
Cuts both ways: ethnicity, poverty, and the social gradient in child welfare interventions

Calum Webb, the University of Sheffield

Paul Bywaters, Huddersfield University

Jonathan Scourfield, Cardiff University

Gavin Davidson, Queen's University Belfast

Lisa Bunting, Queen's University Belfast

\subsection{Introduction}

This article contributes evidence towards a new research agenda advocated by Bywaters, et al. (2019: 145), which goes 'beyond a simplistic bias vs need approach to explaining ethnic disparities in child maltreatment and/or out of home care'. The study builds on existing literature that identifies large inequalities in child protection across ethnic groups

(Bywaters, et al. 2019; Keddell \& Davie, 2018; Kim \& Drake, 2018; Maguire-Jack, et al., 2015; Putnam-Hornstein, et al., 2013; Owen \& Statham, 2009; Tilbury, 2009; Lavergne, et al. 2008). Part of this agenda includes recognising that simplistic models of inequalities in child welfare that treat ethno-racial and economic disparities as distinct components may misrepresent the realities of the child protection system, presenting them as additive rather than intersectional. One dimensional explanations of ethnic inequalities isolated from class - interpersonal racism; stronger extended families; absent fathers - are inadequate to explain the complexities involved.

While this is well understood in social work theory (Nayak \& Robbins, 2018; Mattsson, 2014; Mehrotra, 2010) it is often poorly translated into quantitative analyses and the interpretation of quantitative research findings. This study attempts to take some further steps towards reflecting intersectional theories in our quantitative understanding of inequalities in child and family social work through the use of intersectional population models. There are substantial limitations in our ability to do this, which arise from the quality and coverage of administrative data.

\subsection{Terminology \& Ethnic Group Classification}

Before expressing the aims of this paper, we need to register the language used throughout. We use the ethnic group classifications and naming conventions outlined by the UK Office for National Statistics (2016) that are used in census and administrative data collection. This includes eighteen common ethnic groups in England, eleven of which we consider in our study (the remaining seven are not included due to very low population sizes and incidence rates). This classification structure excludes many ethnic identities that may face hidden prejudice from children's social services.

Further, some readers may be unfamiliar with the convention of referring to the majority White population in the UK with English, Welsh, Scottish, or Northern Irish heritage as 'White British'. The purpose of this is not to deny the 'Britishness' of people of colour, although in practice the naming conventions may have this effect, but to distinguish the White majority in Britain from White minorities in the country, such as White Irish, whose historical and contemporary experiences often differ from those of the 'White British' majority and therefore should not be conflated. 


\subsection{Aims}

We present the results of a multilevel population model analysing the intersection of ethnicity and socioeconomic status, as measured by the English Indices of Multiple Deprivation (Department for Communities and Local Government, 2015). It is important to recognise that this reflects only a very limited intersectional analysis that should be critiqued for its narrow scope (Mehrotra, 2010). The goal of this article is to demonstrate the value of placing ethno-socioeconomic analyses of inequalities within a wider theoretical framework of intersectionality that quantitative social work research can aspire to, and that doing so is essential for incremental changes in administrative data collection that would enable more complex intersectional analyses in the future.

The reasons for focusing on the intersection of ethnicity and socioeconomic status are twofold. The first is related to data availability. Ethnicity is one of the few characteristics of children that is routinely recorded by children's social services in England. Administrative data collected in England are heavily child-focused, with little information about parents recorded. A child's ethnicity is one category from which some information about birth parents can be inferred. Socioeconomic status, similarly, is not routinely recorded but can be studied at the population level by linking household postal codes to small-area measures of deprivation.

The second reason is related to the salience of this particular intersection to contemporary debates in children's social services, and the rich sociological theories that can be applied to better understand the findings emerging from research. Research from the US, UK, and Aotearoa New Zealand has shown that disparities between ethnic groups are not congruous across the spectrum of socioeconomic status (Bywaters, et al. 2019; Kim \& Drake, 2018;

Cram, et al. 2015). Notably, socioeconomic inequalities in interventions are usually greatest for White children. We test whether these findings can be generalised in England and draw on literature that explores the experiences and representations of the White working class in Britain and the US, particularly White working class women in interracial relationships and/or with Mixed Heritage children, to try and explain how such inequalities might be understood and redressed (Newitz \& Wray 1996; Skeggs, 2004; McKenzie 2013; Kouritzin, 2016; Harman, 2010).

\subsection{Ethnic disparities in Child Welfare Interventions}

In the United Kingdom there is an over-representation of Black African and Black Caribbean children in care, and an under-representation of South Asian (Indian, Bangladeshi, and Pakistani) children, relative to their proportions in the wider population (Bywaters, et al. 2017, 2019; Owen \& Statham, 2009). In the USA there are analogous patterns, where Black children are over-represented in child protection statistics and Hispanic children are underrepresented (Maguire-Jack, et al., 2015; Kim \& Drake, 2018; Harris, 2014; PutnamHornstein, et al., 2013). In the United States, Canada, Australia, and Aotearoa New Zealand there are disproportionate numbers of indigenous children taken into care or otherwise in contact with children's social services (Keddell \& Davie, 2018; Harris, 2014; Tilbury, 2009; Lavergne, et al. 2008). 
However, many analyses have also found that this disproportionality varies substantially across the economic spectrum. Bywaters, et al. (2019), Kim \& Drake (2018) and Drake, et al. (2009) found that the over-representation of Black children disappears or substantially decreases when controlling for poverty, and that South Asian (UK) and Hispanic (US) underrepresentation increases under these conditions. Cram, et al. (2015) found that, when comparing Māori and Pākehā substantiated abuse rates of families who had received welfare benefits for four of the past five years and families who had not (as an indicator of poverty), the disproportionality ratio between Māori and Pākehā was higher for families that were not in poverty.

There is no evidence that this disproportionality is a straightforward result of ethnic differences in experiencing abuse and/or neglect. In the UK, analysis of the Crime Survey for England and Wales 2016 by the Office for National Statistics (Flatley, 2016) indicates that there are significant discrepancies between the disproportionality seen in self-reported abuse when compared to the disproportionality seen in child protection interventions. The report shows that the rate ratios of Black, Mixed Heritage, and Asian people reporting historical child abuse to White British people reporting historic child abuse were $0.75: 1$, 1.2:1, and 0.55:1 respectively. By contrast, the rate ratio of combined Child Protection Plan and Children Looked After rates was 1.18:1 for Black children, 1.6:1 for Mixed Heritage children, and 0.4:1 for Asian children (Bywaters, et al. 2019). This leads us to suggest that there is a significant 'supply-side' phenomenon associated with social work practice and policy that contributes to ethnic disproportionality.

\subsection{Deprivation and Child Welfare Interventions}

As highlighted above, ethnic disproportionality is changed significantly after adjustments are made for poverty and deprivation. Deprivation is strongly associated with child welfare interventions (Bywaters, et al., 2018a; 2018b; 2019; Morris, et al., 2018; Pelton, 2015; Coulton, et al., 2007). Many ethnic minority groups, and especially Black African and Black Caribbean populations, face far higher risks of poverty and deprivation (Platt, 2007; 2019; Barnard \& Turner, 2011; Drake, et al. 2009).

The socioeconomic circumstances of families are theorised to have an essential role in the demand for children's services and resultant rates of intervention (Bywaters, et al. 2015, 2018a, 2018b; Pelton, 2015). This is believed to be the consequence of both the direct capacity of families to purchase the essentials for good child development in an unequal society or to solve parenting challenges, and the indirect effects of differential access to resources for the maintenance of psychological well-being and internal and external family relationships (Cooper \& Stewart, 2013, 2017; Mason \& Bywaters, 2016). However, these 'demand-side' factors are inadequate to fully explain why poorer families face higher rates of intervention.

On the supply side, stigmatising discourses in both policy and practice are argued to contribute to an over-representation of poor families within the child protection system (Featherstone, et al., 2018; Morris, et al., 2018; Gibson, 2016; Gupta, 2015; Bray, et al., 2019; ATD Fourth World, N.D.). This structural relationship between socioeconomic circumstances and child welfare intervention rates, which applies across the population as a whole rather than just being a feature of families in poverty, is referred to as the 'social 
gradient' (Bywaters, et al. 2018; Webb, et al. 2020) ), a familiar term in relation to health inequalities. The social gradient alone is able to explain much of the variation in service demand in local authorities in England (Bywaters, et al. 2018a; Webb, et al. 2020).

A tempting explanation for ethnic disproportionality in child welfare interventions is that it simply reflects differential risk of poverty across different ethnic groups and is therefore actually just a reflection of the social gradient. Existing evidence does not support this explanation (Bywaters, et al. 2019). Other possible explanations have not been tested in relation to children's social services, with a more general alternative being drawn from contact theory, that greater intergroup contact can combat prejudice and therefore result in less discriminatory attitudes and that, therefore, disproportionality reflects ethnic segregation (Allport, 1954).

The discussion of some explanations, for example, institutional racism, remains marginal in social work research (Corley \& Young, 2018), with it being especially difficult to disentangle the stigma and prejudice that poor families face from the stigma and prejudice that many Black, Asian, and other ethnic minority families - and couples in interracial relationships experience.

One notable limitation in the existing evidence is a dearth of research into experiences of social work intervention at the affluent end of the socioeconomic scale, where the greatest disproportionalities for Black populations in particular are (Bywaters, et al. 2019; Drake, et al. 2009), and the continued relative disengagement of social work research, sociology, and anthropology, from 'studying up' (Nader, 1972; Gusterson, 1997). Studying up refers broadly to shifting the academic gaze from the typical subjects of research, poor and disempowered children and families, to the affluent and powerful. Not only can this illuminate a fuller spectrum of a phenomenon, but it can often shine a light on the mechanisms by which power and capital shape inequalities and create subjects of the poor (for example, Crossley, 2018; Hastings, 2009). Social workers tend to operate far more in spaces of high poverty, and, by extension, so too do social work researchers, leaving the areas where there is the greatest over-representation of ethnic minority groups underexplored.

\subsection{Race and Class: the Knife that Cuts Both Ways}

The apparent incompatibility between our reality and an obvious additive explanation might suggest that child welfare inequalities are best understood through an intersectional theoretical framework. The term intersectionality was coined by critical race theorist Kimberlé Crenshaw (1989), and is defined by Collins (2009 [1990], p. 277) as "interlocking social institutions [that] have relied on multiple forms of segregation... to produce unjust results". An intersectional framework recognises that the intersections of social institutions including gender, class, ethnicity, age, disability, nationality, and sexual orientation, produce distinct injustices that are not merely reflections of the sum of injustices experienced by each in isolation.

The importance of intersectional theory in social work is not new (Nayak \& Robbins, 2018; Mattsson, 2014; Mehrotra, 2010). Research and practice frameworks have tended to focus on the intersections of ethnic minority identities of service users and the ethnicity, gender, 
class, and sexuality of social workers. The intersections of whiteness and class are largely referred to within a 'reflexive social worker' context, reflecting on the class and ethnic intersectional identity of practitioners and the position of the profession within power structures in Western colonial nations that were founded on the ideology of White supremacy (Jeyasingham, 2012; Mattsson, 2014). There is less reference to whiteness in connection with 'service users' in social work. However, there is an extensive literature on the sociological understanding of whiteness, class, and motherhood, that highlights discrimination and stigma faced by White working-class mothers, particularly those in interracial relationships and/or those who have Mixed Heritage children, who are often the subjects of child protection inquiries.

Research at the intersection of whiteness and class stresses the importance of individual wealth in actualising the affordances of white privilege (Newitz \& Wray, 1996; Wray 2006; Winders, 2003; Skeggs, 2004; Stubblefield, 2007; McKenzie, 2013). This is heavily reflected in cultural constructions of whiteness. In their deconstruction of the term "white trash" as a racialised class identity, Newitz and Wray $(1996$, p. 58) argue that:

"the term 'white trash' reminds us that one of the worst crimes of which one can accuse a person is poverty. If you are white, calling someone 'white' is hardly an insult. But calling someone 'white trash' is both a racist and classist insult. ... Perhaps the scar of race is cut by the knife of class. This is not to say that race is in any way reducible to class. Clearly, the knife cuts both ways. Yet all too often in discussions of racial identity class is ignored, dismissed, and left untheorised."

Newitz \& Wray $(1996$, p. 58)

This depiction of the intersection of whiteness and class, and the stigmatised position of the White working class (especially White working class women), is found in narratives of the 'undeserving underclass' in British society (Haylett, 2001; Skeggs, 2004; Welshman, 2006; McKenzie, 2013). This cultural representation of an 'underclass' is associated with criminality, sexualisation, irresponsibile behaviour, and more recently, backwardness and anti-modernism (Haylett, 2001; Skeggs, 2004; McKenzie 2013).

While such narratives are by no means exclusive to the White working class, nor to Britain (Beddoe, 2014), underclass narratives where racialised White working class identities are centred are common and particularly cruel in politics and popular media, including the rise of the 'poverty porn' genre of 'documentary' (Jensen, 2014; McKenzie, 2015; Threadgold, 2015). The most recent cultural conception of poor-White identity in Britain being the 'chav' - a widely used pejorative term for and stereotype of 'lower'-class young people - who is commonly conjured up in popular culture as a permissible subject of ridicule, derision, subjugation, and discrimination (Tyler, 2008; Jones, 2011; McGarvey, 2017).

This conferred identity carries with it many of the same connotations of criminality and sexual promiscuity that exist in racist stereotypes of Black men and women. The heavily stigmatised intersection of race and class is compounded for mothers of Mixed Heritage children, with White working class women who adopt aspects of African or Caribbean culture and/or form intimate relationships with Black or Asian men being constructed as 'the dirty white', women who had crossed the 'color line' and no longer held a 'pure' White 
ethnic identity (Skeggs, 2004, p. 111; McKenzie, 2013; Harman, 2010; Kouritzin, 2016; Kwan \& Spiers, 2004; Olumide, 2002; Katz, 1996). In Britain, these stereotypes and the degradation of Mixed Heritage children and their White mothers are eerily similar to those constructed as far back as the Fletcher report in 1930, which classified White women in relationships with Black men as either 'mentally weak', 'prostitutes', 'young and reckless', or forced into marriage through pregnancy (Eddo-Lodge, 2017, p.20).

In the United States this ideology of racial purity was formalised in the form of antimiscegenation laws and the 'one drop' rule, outlawing interracial marriages, intimate relationships, and ascribing children's ethnic identity on the basis of their genealogical ancestry where White was a highly protected category. This embedded the stigmatisation of interracial relationships and the children of such unions, and this stigmatisation exists long after the repeal of such laws (Kouritzin, 2016; Kwan \& Spiers, 2004; Dalmage, 2000).

There has been no unanimous shift in disclosed attitudes. Herman \& Campbell, (2012) found as recently as 2008 that 19 per cent of White women surveyed in the Congressional Election Study said that they thought that White women having children with Black men was 'not a good idea'. A further 45 per cent said that they personally 'wouldn't, but that it was okay for others'.

\subsection{Tainted Love and Disgusting Subjects: Cultural denigration of interracial relationships and racialised class identity}

Daryl Carter (2009) charts the portrayal of Black male/White female relationships in postcivil rights US media, illustrating the positioning of White women in interracial relationships as 'traitors to their race' and of Black men as 'dangerous, shiftless, wanton sexual predators lusting after beautiful, chaste young white girls and women.' Similarly, the participants in Lisa McKenzie's $(2013,2015)$ ethnography of the St. Anns Nottingham council estate describe how they were seen as 'tainted' through their associations with Black men and how being labelled as a 'chav' was linked explicitly to the ethnicity of their children, reinforced by portrayals in television.

Shaming is still done with a vulgar openness in British media representations of White working class young mothers (Tyler, 2008; McKenzie 2013). Equivalently coarse and demeaning media depictions of ethnic minority identities are increasingly less common; they do still appear, for example in David Walliams and Matt Lucas' Little Britain or Come Fly with $M e$, but these are often met with an appropriate outcry of disgust. White working class mothers, by contrast, continue in British culture to be permitted subjects of ridicule. For example, see the relative indifference towards Vicky Pollard in Little Britain, or Lauren Cooper in the Catherine Tate Show, to the extent that campaign teams for both major political parties in the UK felt comfortable invoking them (Eaton, 2010).

What these examples highlight is the heavily racialised notion of class that results from poverty being seen as particularly abherrent alongside White identity and, by extension, relative wealth and affluence being considered abnormal when occuring alongside 'nonWhiteness'. Newitz \& Wray (1996) and Wray (2006) highlight that within multicultural Western societies, being both poor and White is frequently constructed as an individual moral failure, an inability to gain socioeconomic status despite the advantages conferred by 
Whiteness, or a failure to act according to a middle-class construction of Whiteness. Stereotypes of this racialised identity are rarely challenged.

Poverty and 'non-Whiteness' may be more empathetically interpreted as a consequence of racist and colonial power structures, in progressive interpretations that many social workers share, or treated as a sociobiological consequence of racial differences that is also outside of the individual's control, in racist interpretations. This is not to say that ethnic minority populations are not subject to racist individualistic narratives, but that even racist interpretations of ethnic socioeconomic disparities are often rooted in structural (biological), rather than individual, explanations.

\subsection{Structural Narratives of Inequality in Social Work}

With regards to social work practice, structural narratives about the child welfare consequences of poverty have increasingly entered the professional consciousness in recent years, but an individualised narrative of personal choice and personal failings has dominated wider policy discourse for decades, if not centuries (Walker, 2014; O'Hara 2020). Despite a historic commitment from the profession to people living in poverty, the treatment of poverty in social work education has been described as 'extraordinarily superficial' (KrumerNevo, et al., 2009, p. 226), failing to adequately prepare students to challenge individualised narratives of poverty or to respond to class-inequality (Strier, 2009).

In many ways, social work has, or had been, far ahead of the curve in incorporating learning about structural disadvantage into education and decision-making, especially in relation to race, to the extent that the profession has been attacked by tabloid media for its 'obsession' with 'political correctness' more or less consistently since at least the 1990s (Lavalette \& Penketh, 2013; Dominelli, 2017). However, there is a disconnect in the translation from antioppressive theory to anti-oppressive practice when balancing the assessment of competing injustices. For example, under the Equalities Act 2010 in England, socioeconomic status or class is not considered a protected characteristic while race is.

Similarly, there are no such protections from discrimination on the grounds of socioeconomic class in most other countries. In the United States, under the Civil Rights Act of 1964, the Fair Housing Act and the Americans with Disabilities Act, protections are provided for race, sex, religion, national origin, age, and disability, but not for class. In Australia, race, ethnicity, national origin, sex, gender identity, relationship status, and disability are protected characteristics covered by various Discrimination Acts. Article 14 of the European Convention on Human Rights offers protection from discrimination on the basis of sex, race, language, religion, opinion, national origin, association with property, or any 'other' status. One might then argue that class is reflected in this 'other status' category, but in existing case law this has only been applied in relation to sexual orientation, illegitimacy, marital status, trade union membership, 'transsexual status', imprisonment, age, and disability (Equality \& Human Rights Commission, 2018). Never class.

There is therefore a legal imperative for children's services to be able to demonstrate that they are not discriminating on the basis of a person's ethnicity. In practice this usually means not discriminating against people of colour, rather than more broadly considering the role that race plays in all decision making. The same impetus does not exist for 
socioeconomic or class differences. While individual social workers may do so, there is no oversight to identify class discrimination, and therefore far less incentive to protect people from discrimination on the basis of their class identity.

\subsection{Research Questions, Data, and Methods}

We attempt to answer the following research questions:

- How do overall intervention rates differ for different ethnic groups after controlling for deprivation and differential social gradients?

- Is the social gradient in child welfare interventions statistically significant for all ethnic populations within Middle-layer Super Output Areas (MSOAs, defined below) and how does it differ between ethnic groups?

- Is MSOA ethnic density associated with MSOA ethnic population differences in intervention rates?

Child-level analysis is not possible in the UK due to the absence of information on children not already known to children's services in administrative data. This study aggregates children's social services data from a stratified sample of local authorities and combines this with several publicly available data sources as well as Gini coefficients (a measure of socioeconomic inequality) derived from CACI Paycheck data (CACI Ltd, 2019) at the Middle-Layer Super Output Area (MSOA) level. In order to explore differences between ethnic populations, we used a multilevel model examining MSOA ethnic group child populations.

\subsection{Data}

MSOAs are a type of geospatial statistical unit used by the English and Welsh government statistical authority, structured based on geographical areas that contain approximately equal population sizes. Output Areas form the lowest level geostatistical unit for census and other data collection, and are roughly analogous to census tracts in other countries. Much data at Output Area level is too sensitive to be released, and is aggregated to the Lowerlevel Super Output Area (LSOA) level. MSOAs are combinations of four or five LSOAs, each of which contains a population of around 1600. MSOAs therefore have an average population size of around 7,200 with a minimum of 5,000 and maximium of 15,000. It was necessary to use MSOA-level analysis as opposed to LSOA-level analysis due to the small populations of some ethnic populations and the amalgamation of ethnic groups with diverse histories in statistical releases at the LSOA level.

There are 152 local authorities in England with responsibility for providing children's services. Following the usual convention of excluding two very small LAs, the City of London and the Isles of Scilly, the remaining 150 have an average child population (age $0-17$ ) of just under 80,000 with a range from around 8,000 to over 330,000 . Children's services data was secured for all children referred to social services in a sample of local authorities including details about age, gender, ethnicity, 'child in need' status (CIN), child protection plan (CPP) status, and child looked after (CLA) status, at $31^{\text {st }}$ March 2015. Ethical approval for the study was obtained from the Coventry University Faculty Research Ethics Committee and support was secured from the Association of Directors of Children's Services in England. 
Child in Need status refers to the definition of need outlined in the Children Act 1989. For a child to be deemed 'in Need' they must be unlikely to 'achieve or maintain, or have the opportunity of achieving or maintaining, a reasonable standard of health or development without the provision for them of services by a local authority'; or, 'their health or development is likely to be significantly impaired, or further impaired, without the provision for them of such services'; or, if they are disabled. A Child Protection Plan is drawn up with social workers if statutory assessments of need meet a significant threshold of immediate risk, reflecting a high-level of intervention. A child that is looked after has been removed from their birth family and is now under the care of the local authority. Children that are subsequently adopted are no longer counted as 'Children Looked After'.

CPP and CLA data were drawn from 18 local authorities covering all regions of England with a collective population of over 1.3 million ( $>12 \%$ of England) children from the eleven ethnic groups included in this study. This stratified sample was selected based on several characteristics, including region, level of deprivation, and proportion of each ethnic group population in England. CIN data were Missing At Random (de Leeuw \& Hox, 2008) for five local authorities. The $\mathrm{CIN}$ analysis therefore represents data covering approximately 860,000 children from the eleven included ethnic groups. Summary statistics are split between the CIN sample (13) and the CPP/CLA sample (18). Based on the similarity of the summary statistics and the 'Missing at Random' nature of missing CIN data, the findings should still be representative of England. Data on individual children were linked to the MSOA code of their parental home or the parental home from which they entered care in the case of children looked after.

Ethnic density was calculated by taking the percentage of the population in each MSOA that identified as each of the ethnic populations in the study (shown in Table 1). Black African, Black Caribbean, Black Other, and all Mixed Heritage groups had MSOA population density levels with correlations greater than $r=0.9$, so were combined into Black (All) population density and Mixed Heritage (All) population density variables to avoid multicollinearity. The proportion of the child population identified as White British in our sample LAs varied greatly, from over $94 \%$ to below $15 \%$.

MSOA-level data included 2015 Index of Multiple Deprivation (IMD) score and estimates of child population size by ethnic group. The IMD consists of several domains of deprivation, weighted as follows: income deprivation (22.5\%); employment deprivation (22.5\%); education, skills and training deprivation (13.5\%); health deprivation and disability $(13.5 \%)$; crime (9.3\%); barriers to housing and services (9.3\%); and living environment deprivation (9.3\%) (Department for Communities and Local Government, 2015). A one standard deviation increase in deprivation was associated with around a 10 per cent increase in the proportion of households on a relative low income (Webb, et al. 2020).

Income inequality before housing costs is estimated from summary data of household income from CACI Ltd's Paycheck data set (2019) and was included as a control for social gradient interaction effects, as our recent research has shown that the social gradient is strongly associated with the overall local authority income inequality (Webb, et al. 2020). Estimates of income inequality were based on income distribution simulations (CACl, Ltd. 2019). 
Summary statistics for all dependent and independent variables used are transcribed in table 1. Variables were standardised and group- (MSOA level) or grand-mean (LA-level) centred to aid interpretation.

\subsection{Methods}

Multilevel negative binomial models were used, with an exposure variable for the natural log of the population size divided by 10,000 , to make model predictions comparable to standard reporting of rates in England. Multilevel models allow researchers to control for autocorrelation caused by clustering within group membership (Tabachnick \& Fidell, 2014; Robson \& Pevalin, 2015), for example, to control for the fact that one local authority's children's services may have higher rates of intervention overall, or that different ethnic populations within the same MSOA may have more similar rates than they would if they were in different MSOAs.

Each MSOA was broken into 11 distinct ethnic populations, creating a three-level structure of MSOA ethnic populations that are nested in MSOAs which are nested in local authorities. MSOA 'subpopulations' with zero population of an ethnic group were excluded from analyses. Random effects were estimated for the relationship between ethnic group population and intervention rates depending on their local authority membership, and random intercepts were estimated for rates in local authorities and MSOAs to control for clustering. This differs from other approaches that have estimated multiple models for data representing geographical rates for each ethnic group (e.g. Kim \& Drake, 2018). Either approach should provide similar estimates, but including ethnic group population identifiers as a level in a multilevel model allows for more efficient scaling of analysis and postestimation options when dealing with a large number of distinct ethnic groups.

All analyses and data tidying were conducted in $R$. Models were fit using the glmmTMB package (Brooks, et al. 2017) and postestimation of estimated marginal means used the emmeans package (Lenth, 2019). To illustrate the nature of child protection inequalities at the intersection of ethnic group and socioeconomic status we estimated social gradients in interventions and their significance for each ethnic group, and ethnic Incidence Rate Ratios (IRRs) and their significance between ethnic minority groups and the White British ethnic group and within each ethnic group at high and low levels of socioeconomic deprivation.

\begin{tabular}{|c|c|c|c|c|c|}
\hline & Mean & Median & SD & Min & Max \\
\hline MSOA Ethnic Population Level $i$ & & & & & \\
\hline Children in Need Count & 4.250 & 0 & 15.2 & 0 & 201 \\
\hline $\begin{array}{l}\text { Child Protection Plan Count } \\
N=7824\end{array}$ & 0.805 & 0 & 2.77 & 0 & 63 \\
\hline $\begin{array}{l}\text { Children Looked After Count } \\
\mathrm{N}=7824\end{array}$ & 0.805 & 0 & 3.43 & 0 & 59 \\
\hline MSOA lev & & & & & \\
\hline White British Pop. Density (\%) & 77.6 & 86.55 & 22.28 & 13.44 & 94.88 \\
\hline Asian Bangladeshi Pop. Density (\%) & 1.01 & 0.46 & 1.43 & 0.05 & 4.34 \\
\hline
\end{tabular}




\begin{tabular}{|c|c|c|c|c|c|}
\hline Asian Indian Pop. Density (\%) & 3.21 & 1.27 & 3.86 & 0.18 & 14.00 \\
\hline Asian Pakistani Pop. Density (\%) & 2.36 & 0.59 & 3.08 & 0.07 & 9.28 \\
\hline Black (All) Pop. Density (\%) & 4.25 & 1.16 & 8.34 & 0.20 & 29.10 \\
\hline $\begin{array}{l}\text { Mixed Heritage (All) Pop. Density } \\
\text { (\%) }\end{array}$ & 4.18 & 3.83 & 2.26 & 2.20 & 10.30 \\
\hline MSOA IMD Score & 21.35 & 16.24 & 14.57 & 3.16 & 71.11 \\
\hline \multicolumn{6}{|l|}{$N=543$} \\
\hline \multicolumn{6}{|l|}{ MSOA level $j$ (CPP/CLA) } \\
\hline White British Pop. Density (\%) & 75.38 & 83.92 & 23.44 & 13.44 & 94.88 \\
\hline Asian Bangladeshi Pop. Density (\%) & 1.05 & 0.57 & 1.51 & 0.05 & 6.43 \\
\hline Asian Indian Pop. Density (\%) & 3.32 & 1.67 & 4.89 & 0.18 & 22.23 \\
\hline Asian Pakistani Pop. Density (\%) & 2.24 & 0.50 & 3.16 & 0.07 & 9.97 \\
\hline Black (All) Pop. Density (\%) & 4.46 & 1.16 & 7.24 & 0.20 & 29.15 \\
\hline $\begin{array}{l}\text { Mixed Heritage (All) Pop. Density } \\
(\%)\end{array}$ & 4.99 & 4.03 & 3.31 & 2.20 & 14.82 \\
\hline MSOA IMD Score & 21.58 & 17.71 & 14.05 & 2.74 & 71.75 \\
\hline \multicolumn{6}{|l|}{$N=836$} \\
\hline \multicolumn{6}{|l|}{ LA level $k$ (CIN) } \\
\hline LA IMD Score & 23.67 & 26.64 & 9.66 & 8.86 & 41.24 \\
\hline LA Gini Coefficient & 0.389 & 0.385 & 0.0168 & 0.358 & 0.415 \\
\hline \multicolumn{6}{|l|}{$N=13$} \\
\hline \multicolumn{6}{|l|}{ LA level $k$ (CPP/CLA) } \\
\hline LA IMD Score & 23.71 & 25.63 & 9.16 & 8.86 & 41.24 \\
\hline LA Gini Coefficient & 0.387 & 0.384 & 0.0167 & 0.358 & 0.415 \\
\hline$N=18$ & & & & & \\
\hline
\end{tabular}

\subsection{Data Limitations}

Some uncertainties surround the consistency with which particular ethnic categories are ascribed to individuals. In children's services data, ascription may be made by a social worker or other member of staff, not necessarily by the individuals concerned. In population data generally, any of the categories of Black Caribbean, Black African and Black Other might be chosen by some Black people for different reasons in different circumstances. Black people whose ancestors were transported as slaves from Africa to the Caribbean clearly have a choice to make about their heritage. For some, identification is an overtly political act.

The Mixed Heritage category is also fraught with potential for inconsistency of ascription, especially where this is done by a social worker. There is a risk that the category of 'Mixed Heritage (Other)' is used as a convenient catch-all for children whose parentage cannot be determined or does not fall into one of the limiting pairings that the statistical authority has constructed. Differences between Mixed Heritage populations should be interpreted with some caution.

Ethnic populations in England have grown at varied rates since 2011 as a result of differential demographics, variations in birth rates and migration, so attributing the same growth rate to all ethnic populations to estimate population size within an MSOA necessarily introduces some unknown error. As a result, for example, there were some 
illogical populations where the number of children in need, on child protection plans, or taken into care exceeded the estimated population. These were excluded from the analysis to avoid the creation of leverage points.

MSOA Index of Multiple Deprivation (IMD) scores were used as a measure of poverty and socioeconomic status. There are two limitations with this widely used approach. First, using MSOA rather than LSOA level scores reduces the likelihood of a good fit between the neighbourhood average and the experience of families. Second, using average deprivation scores for larger populations reduces the range of those scores. This means that the scale and impact of inequality in children's socio-economic circumstances is likely underestimated. While these findings have consequences for families and children, we try to limit our discussion of results to the population level where possible so as not to overreach our conclusions.

Further, it is likely that using neighbourhood IMD scores as a proxy for family socioeconomic circumstances works less well for some ethnic groups than it does for others. Ethnic minority families may be more likely to choose to remain close to other members of their family or community rather than move, because of the possibility or fear of encountering negative attitudes and behaviours when moving to predominately White areas (Archer \& Stevens, 2018). There are also discriminatory obstacles to free movement in the housing market (Gulliver, 2016). This risks creating a lower correlation between individual wealth and place than might be found in White populations. These limitations present difficulties in assessing whether findings are due to data aggregation artefacts or reflect 'real' societal patterns. More definitive answers can only be gleaned from individual/household level data.

\subsection{Results}

Results from the regression models are transcribed in table 2 below. The IRR column refers to the incidence rate ratio associated with a one unit change in the independent variable, relative to the intercept of the model. The mean of a standardised variable is set to zero, which becomes equivalent to the mean of the unstandardized variable. Plus one and minus one standard deviations of the standardised variable are roughly equivalent to the average value in the highest third of all responses and the average value in the lowest third of all responses. For example, zero on a standardised IMD score would be equal to 21.58 on an unstandardized IMD score, and zero plus one standard deviation would be equal to 21.58 plus 9.66 (table 1). All continuous variables are centred around their mean, so the IRR refers to the ratio between the rate at a value of one and the rate at the mean value of the variable.

A one-unit increase for a categorical independent variable, like ethnic group, refers to the incidence rate ratio between that group and the reference category. In this case, White British neighbourhood populations are the reference category. For example, if the IRR for a given ethnic group variable is equal to 2 this would indicate that there were twice as many occurrences of the intervention in that ethnic population group than in the White British population group, all else being equal. An IRR between zero and one indicates a lower rate compared to the reference group; for example, an IRR of 0.5 would indicate that particular ethnic group had approximately half the rate of the White British reference category. In 
other words, for every two White British children per 10,000 White British children we would expect rates of one child from the other ethnic group per 10,000 of that group's population. Incidence rates and incidence rate ratios between ethnic groups at differing levels of neighbourhood deprivation are visualised in an online supplementary figure.

\subsection{Ethnic inequalities in Intervention Rates}

At average levels of deprivation 5 (CIN) or 6 (CPP/CLA) ethnic minority populations had significantly different levels of child welfare interventions when compared to White British MSOA populations, but there were no simplistic universal patterns. Indian, Mixed Heritage (Other), and Mixed White \& Black Caribbean ethnic populations had intervention rates that differed significantly from White British populations across all three types of intervention. Asian Pakistani rates differed significantly for child protection plan interventions and for rates of children taken into care. Black Caribbean populations had significantly different $\mathrm{CIN}$ and CLA intervention rates. Asian Bangladeshi and Black African populations had significantly different CIN rates only and Mixed White/Black African populations had significantly different CPP rates only. Only two ethnic minority populations did not differ significantly from the White British population in any type of intervention: Black Other and Mixed Heritage White \& Asian.

At average levels of deprivation, Indian MSOA populations had significantly lower rates across all three types of intervention. All else being equal, Indian populations had CIN incidence rates that were around 30.7 per cent of the predicted White British rate. CPP rates were 27.8 per cent of the White British rate, and predicted CLA rates were only around 13.3 per cent of the White British rate.

By contrast, rates for Mixed Other and Mixed White/Black Caribbean populations were significantly higher for all types of intervention. This was particularly pronounced for the Mixed Heritage (Other) category, which had CIN rates approximately 3 times higher than the equivalent White British population; CPP rates approximately 2.8 times higher; and CLA rates approximately 2.6 times higher, holding all else constant. For Mixed White \& Black Caribbean populations the rates were 1.3, 1.8 and 1.4 times higher than the White British rates for CIN, CPP, and CLA respectively.

Pakistani populations had significantly lower child protection plan and children looked after rates, but not significantly different children in need rates. For Pakistani populations, CPP rates were only around 37 per cent of the White British rates and CLA rates were only 33 per cent of the White British population rates. Black Caribbean populations had significantly higher CIN and CLA rates, at around 1.5 and 1.9 times the White British rate respectively.

Lastly, three ethnic populations differed significantly on only one type of intervention. Bangladeshi MSOA populations had CIN rates that were around 69 per cent of the White British rate. CIN rates for Black African populations were around 1.2 times higher. Mixed Heritage White \& Black African populations had CPP rates that were around 1.6 times higher holding all else equal. 
Table 2: Multilevel Negative Binomial Regression Models predicting intervention rates within MSOA ethnic populations

\begin{tabular}{|c|c|c|c|c|c|c|c|c|c|c|c|c|c|c|c|}
\hline & \multicolumn{5}{|c|}{ Children in Need Rate (within MSOA Ethnic Population) } & \multicolumn{5}{|c|}{ CPP rate (within MSOA Ethnic Population) } & \multicolumn{5}{|c|}{ Children Looked After (within MSOA Ethnic Population) } \\
\hline & B & SE & $\mathrm{t}$ & IRR & p & B & SE & $\mathbf{t}$ & IRR & p & B & SE & $\mathbf{t}$ & IRR & p \\
\hline Intercept/Constant & 5.535 & 0.088 & 63.011 & 253.432 & $* * *$ & 3.436 & 0.06 & 56.835 & 31.075 & $* * *$ & 3.737 & 0.036 & 104.703 & 41.958 & $* * *$ \\
\hline \multicolumn{16}{|l|}{ MSOA Ethnic Population Level } \\
\hline Asian Bangladeshi & -0.366 & 0.182 & -2.014 & 0.693 & * & -0.915 & 0.625 & -1.464 & 0.4 & & -0.406 & 0.238 & -1.708 & 0.667 & \\
\hline Asian Indian & -1.182 & 0.19 & -6.217 & 0.307 & $* * *$ & -1.282 & 0.252 & -5.08 & 0.278 & $* * *$ & -2.018 & 0.374 & -5.398 & 0.133 & $* * *$ \\
\hline Asian Pakistani & -0.403 & 0.211 & -1.906 & 0.668 & & -0.992 & 0.414 & -2.398 & 0.371 & * & -1.095 & 0.33 & -3.32 & 0.334 & $* * *$ \\
\hline Black African & 0.176 & 0.081 & 2.16 & 1.192 & * & -0.533 & 0.295 & -1.805 & 0.587 & & 0.244 & 0.184 & 1.33 & 1.277 & \\
\hline Black Caribbean & 0.415 & 0.138 & 3.015 & 1.514 & $* *$ & -0.192 & 0.283 & -0.677 & 0.826 & & 0.648 & 0.257 & 2.517 & 1.912 & * \\
\hline Black Other & 0.097 & 0.142 & 0.684 & 1.102 & & -0.292 & 0.568 & -0.513 & 0.747 & & 0.125 & 0.336 & 0.372 & 1.133 & \\
\hline Mixed Other & 1.082 & 0.086 & 12.542 & 2.949 & $* * *$ & 1.032 & 0.167 & 6.166 & 2.807 & $* * *$ & 0.965 & 0.125 & 7.725 & 2.624 & $* * *$ \\
\hline Mixed White/Asian & -0.027 & 0.116 & -0.235 & 0.973 & & -0.25 & 0.281 & -0.892 & 0.779 & & 0.029 & 0.153 & 0.189 & 1.029 & \\
\hline Mixed White/Bl. African & 0.036 & 0.199 & 0.182 & 1.037 & & 0.472 & 0.209 & 2.259 & 1.603 & $*$ & -0.008 & 0.206 & -0.038 & 0.992 & \\
\hline Mixed White BI. Caribbean & 0.264 & 0.11 & 2.408 & 1.302 & $*$ & 0.607 & 0.186 & 3.264 & 1.836 & $* *$ & 0.369 & 0.152 & 2.419 & 1.446 & * \\
\hline \multicolumn{16}{|l|}{ MSOA Level } \\
\hline MSOA IMD (z-score) & 1.161 & 0.055 & 21.198 & 3.194 & $* * *$ & 1.487 & 0.101 & 14.776 & 4.423 & $* * *$ & 1.359 & 0.061 & 22.263 & 3.891 & $* * *$ \\
\hline Asian Bangladeshi Population Density \% & -0.049 & 0.079 & -0.621 & 0.952 & & 0.001 & 0.039 & 0.023 & 1.001 & & 0.001 & 0.024 & 0.03 & 1.001 & \\
\hline Asian Indian Population Density \% & -0.034 & 0.043 & -0.779 & 0.967 & & -0.025 & 0.017 & -1.494 & 0.975 & & 0.002 & 0.011 & 0.165 & 1.002 & \\
\hline Asian Pakistani Population Density \% & 0.006 & 0.047 & 0.125 & 1.006 & & -0.028 & 0.034 & -0.845 & 0.972 & & 0.036 & 0.02 & 1.765 & 1.036 & \\
\hline Black Af/Crb/Oth Population Density \% & -0.035 & 0.019 & -1.828 & 0.965 & & -0.009 & 0.013 & -0.679 & 0.991 & & -0.01 & 0.008 & -1.237 & 0.99 & \\
\hline Mixed Heritage Population Density \% & 0.109 & 0.093 & 1.175 & 1.115 & & 0.086 & 0.033 & 2.597 & 1.09 & $* *$ & -0.035 & 0.02 & -1.732 & 0.966 & \\
\hline \multicolumn{16}{|l|}{ LA Level } \\
\hline LA IMD (z-score) & 0.234 & 0.11 & 2.117 & 1.263 & * & -0.223 & 0.124 & -1.801 & 0.8 & & 0.221 & 0.071 & 3.121 & 1.247 & $* *$ \\
\hline LA Gini (z-score) & 0.067 & 0.136 & 0.49 & 1.069 & & 0.406 & 0.128 & 3.162 & 1.5 & $* *$ & 0.087 & 0.076 & 1.145 & 1.091 & \\
\hline \multicolumn{16}{|l|}{ Cross-level Interactions } \\
\hline LA IMD * MSOA IMD & 0.095 & 0.076 & 1.255 & 1.099 & & 0.095 & 0.122 & 0.774 & 1.099 & & -0.033 & 0.086 & -0.385 & 0.968 & \\
\hline LA Gini * LSOA IMD & 0.135 & 0.069 & 1.967 & 1.145 & * & 0.252 & 0.115 & 2.188 & 1.287 & * & 0.237 & 0.081 & 2.907 & 1.267 & $* *$ \\
\hline MSOA IMD * Asian Bangladeshi & -1.149 & 0.272 & -4.219 & 0.317 & $* * *$ & -1.898 & 0.544 & -3.492 & 0.15 & $* * *$ & -1.351 & 0.381 & -3.543 & 0.259 & $* * *$ \\
\hline MSOA IMD * Asian Indian & -0.963 & 0.19 & -5.08 & 0.382 & $* * *$ & -0.784 & 0.386 & -2.032 & 0.457 & * & -1.24 & 0.489 & -2.536 & 0.289 & * \\
\hline MSOA IMD * Asian Pakistani & -0.682 & 0.172 & -3.97 & 0.505 & $* * *$ & 0.211 & 0.412 & 0.512 & 1.235 & & -0.561 & 0.373 & -1.503 & 0.571 & \\
\hline MSOA IMD* Black African & -0.798 & 0.154 & -5.187 & 0.45 & $* * *$ & -0.975 & 0.318 & -3.067 & 0.377 & $* *$ & -1.23 & 0.19 & -6.487 & 0.292 & $* * *$ \\
\hline MSOA IMD * Black Caribbean & -0.832 & 0.225 & -3.695 & 0.435 & $* * *$ & -0.507 & 0.434 & -1.167 & 0.602 & & -0.729 & 0.271 & -2.693 & 0.482 & $* *$ \\
\hline MSOA IMD * Black Other & -1.244 & 0.215 & -5.795 & 0.288 & $* * *$ & -2.019 & 0.379 & -5.322 & 0.133 & $* * *$ & -1.399 & 0.299 & -4.674 & 0.247 & $* * *$ \\
\hline MSOA IMD * Mixed Other & -0.058 & 0.114 & -0.508 & 0.944 & & -0.517 & 0.209 & -2.467 & 0.597 & * & -0.352 & 0.165 & -2.136 & 0.703 & * \\
\hline MSOA IMD * White/Asian & -0.074 & 0.134 & -0.55 & 0.929 & & 0.015 & 0.266 & 0.057 & 1.015 & & -0.26 & 0.196 & -1.323 & 0.771 & \\
\hline MSOA IMD* M. Wh/BI. African & -0.868 & 0.201 & -4.321 & 0.42 & $* * *$ & -1.327 & 0.302 & -4.397 & 0.265 & $* * *$ & -0.873 & 0.284 & -3.079 & 0.418 & ** \\
\hline MSOA IMD * M. Wh/BI. Caribbean & -0.635 & 0.139 & -4.558 & 0.53 & $* * *$ & -1.128 & 0.224 & -5.044 & 0.324 & $* * *$ & -0.626 & 0.188 & -3.33 & 0.535 & $* * *$ \\
\hline
\end{tabular}


Table 2: Multilevel Negative Binomial Regression Models predicting intervention rates within MSOA ethnic populations (cont.)

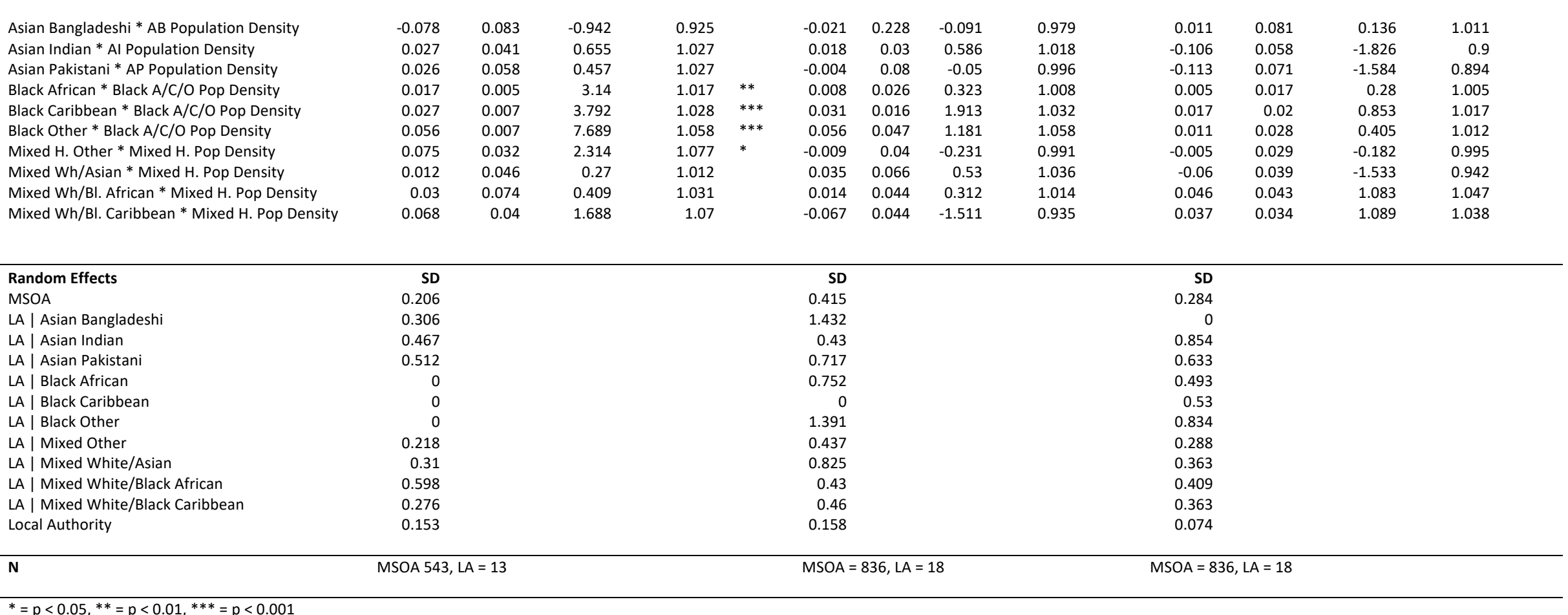


While the scale of this ethnic disproportionality is shocking in itself, greater ethnic inequalities emerge when incidence rate ratios are compared at high or low levels of MSOA deprivation, as opposed to comparing incidence rate ratios at the mean point of deprivation. IRR comparisons at minus one standard deviation and plus one standard deviation of IMD scores are transcribed with significance indicators in table three. Column $\mathrm{p}_{1}$ shows whether the IRR between the ethnic group and the White British population is statistically significant. Column $\mathrm{p}_{2}$ shows whether there is a significant difference between the IR at one standard deviation of MSOA IMD score and the IR at minus one standard deviation of MSOA IMD score for each ethnic group. Model IRs and IRRs are also visualised between -1SD and +1SD for each ethnic group in a supplementary figure.

At low levels of neighbourhood deprivation, eight ethnic groups had significant CIN and CLA incidence rate ratios and seven had significant CPP incidence rate ratios. Seven of the eight significant CIN and CLA IRRs and six of the seven CPP IRRs were greater than one, indicating higher incidence of interventions for those ethnic groups in low deprivation MSOAs than White British populations, all else being equal. For example, in low deprivation MSOAs there were four times (IRR $=3.98$ ) higher rates for Black Caribbean children in care than White children, per 10,000 of their respective population.

At high levels of deprivation, the direction of the IRRs for all but Mixed Heritage (Other) child populations was reversed. All of the eight significant IRRs for CIN, six of the seven IRRs for CPP, and seven of the eight significant IRRs for CLA were less than one, indicating a lower incidence rate relative to the rate for White British child populations.

Table 3. Incidence Rate Ratios and significance at low and high levels of neighbourhood deprivation relative to White British populations

\begin{tabular}{|c|c|c|c|c|c|c|c|c|c|c|c|c|c|c|c|}
\hline & \multicolumn{5}{|c|}{ Children in Need } & \multicolumn{5}{|c|}{ Child Protection Plans } & \multicolumn{5}{|c|}{ Children Looked After } \\
\hline & \multicolumn{2}{|c|}{ Low IMD } & \multicolumn{2}{|c|}{ High IMD } & \multirow[b]{2}{*}{$\mathbf{p}_{2}$} & \multicolumn{2}{|c|}{ Low IMD } & \multicolumn{2}{|c|}{ High IMD } & \multirow[b]{2}{*}{$\mathbf{p}_{2}$} & \multicolumn{2}{|c|}{ Low IMD } & \multicolumn{2}{|c|}{ High IMD } & \multirow[b]{2}{*}{$\mathbf{p}_{2}$} \\
\hline & IRR & $p_{1}$ & IRR & $p_{1}$ & & IRR & $\mathbf{p}_{1}$ & IRR & $p_{1}$ & & IRR & $p_{1}$ & IRR & $p_{1}$ & \\
\hline Asian Bangladeshi & 2.19 & $* * *$ & 0.22 & $* * *$ & & 2.67 & $* * *$ & 0.06 & $* * *$ & & 2.30 & $* * *$ & 0.17 & $* * *$ & \\
\hline Asian Indian & 0.80 & $* * *$ & 0.12 & $* * *$ & & 0.61 & $*$ & 0.13 & $*$ & & 0.44 & $*$ & 0.04 & $*$ & \\
\hline Asian Pakistani & 1.32 & $* * *$ & 0.34 & $* * *$ & & 0.30 & & 0.46 & & $* *$ & 0.54 & & 0.18 & & \\
\hline Black African & 2.65 & $* * *$ & 0.54 & $* * *$ & * & 1.56 & $* *$ & 0.22 & $* *$ & & 3.98 & $* * *$ & 0.37 & $* * *$ & \\
\hline Black Caribbean & 3.48 & $* * *$ & 0.66 & $* * *$ & & 1.37 & & 0.50 & & $*$ & 3.35 & $* *$ & 0.84 & $* *$ & \\
\hline Black Other & 3.82 & $* * *$ & 0.32 & $* * *$ & & 5.62 & $* * *$ & 0.10 & $* * *$ & & 3.81 & $* * *$ & 0.27 & $* * *$ & \\
\hline Mixed Other & 3.12 & & 2.78 & & $* * *$ & 4.71 & $*$ & 1.67 & $*$ & $* * *$ & 3.41 & $*$ & 1.74 & $*$ & $* * *$ \\
\hline Mixed White/Asian & 1.05 & & 0.90 & & $* * *$ & 0.77 & & 0.79 & & $* * *$ & 1.26 & & 0.76 & & $* * *$ \\
\hline $\begin{array}{l}\text { Mixed White/BI. } \\
\text { African }\end{array}$ & 2.47 & $* * *$ & 0.44 & $* * *$ & & 6.04 & $* * *$ & 0.43 & $* * *$ & & 2.07 & $* *$ & 0.40 & $* *$ & \\
\hline $\begin{array}{l}\text { Mixed White BI. } \\
\text { Caribbean }\end{array}$ & 2.46 & $* * *$ & 0.69 & $* * *$ & $* *$ & 5.67 & $* * *$ & 0.59 & $* * *$ & & 2.49 & $* *$ & 0.74 & $* *$ & $* *$ \\
\hline White British & 1 & - & 1 & - & $* * *$ & 1 & - & 1 & - & $* * *$ & 1 & - & 1 & - & $* * *$ \\
\hline
\end{tabular}

$\mathrm{p}_{2}=$ Whether IR at +1SD MSOA IMD is significantly different from IR at -1SD MSOA IMD

\subsection{Ethnicity and the Social Gradient}

These differences may be a function of differing social gradients emerging through the racialised notion of class and poverty. Differential social gradients can be calculated for each ethnic group by combining the estimates for MSOA IMD z-score and the interaction between MSOA IMD z-score and ethnic group, and then exponentiating the result to 
calculate the incidence rate ratio between a one standard deviation increase in deprivation and the mean for each ethnic population. A value of 2 would indicate the rate of intervention doubling for each one standard deviation increase in neighbourhood deprivation. We refer to the result as a 'social gradient'. This expression of socioeconomic inequalities has been used in previous work to provide a single number to summarise socioeconomic inequality (Webb, et al. 2020).

Social gradients for each ethnic population are shown in figure one and transcribed with 95 per cent confidence intervals and inference summaries in table 3 . There are notable differences not only between the social gradients for each ethnic population, but across different types of intervention.

Figure 1: The relationship between MSOA deprivation and MSOA child welfare interventions for each ethnic population. Higher social gradients reflect greater socioeconomic child welfare inequalities in that ethnic population.

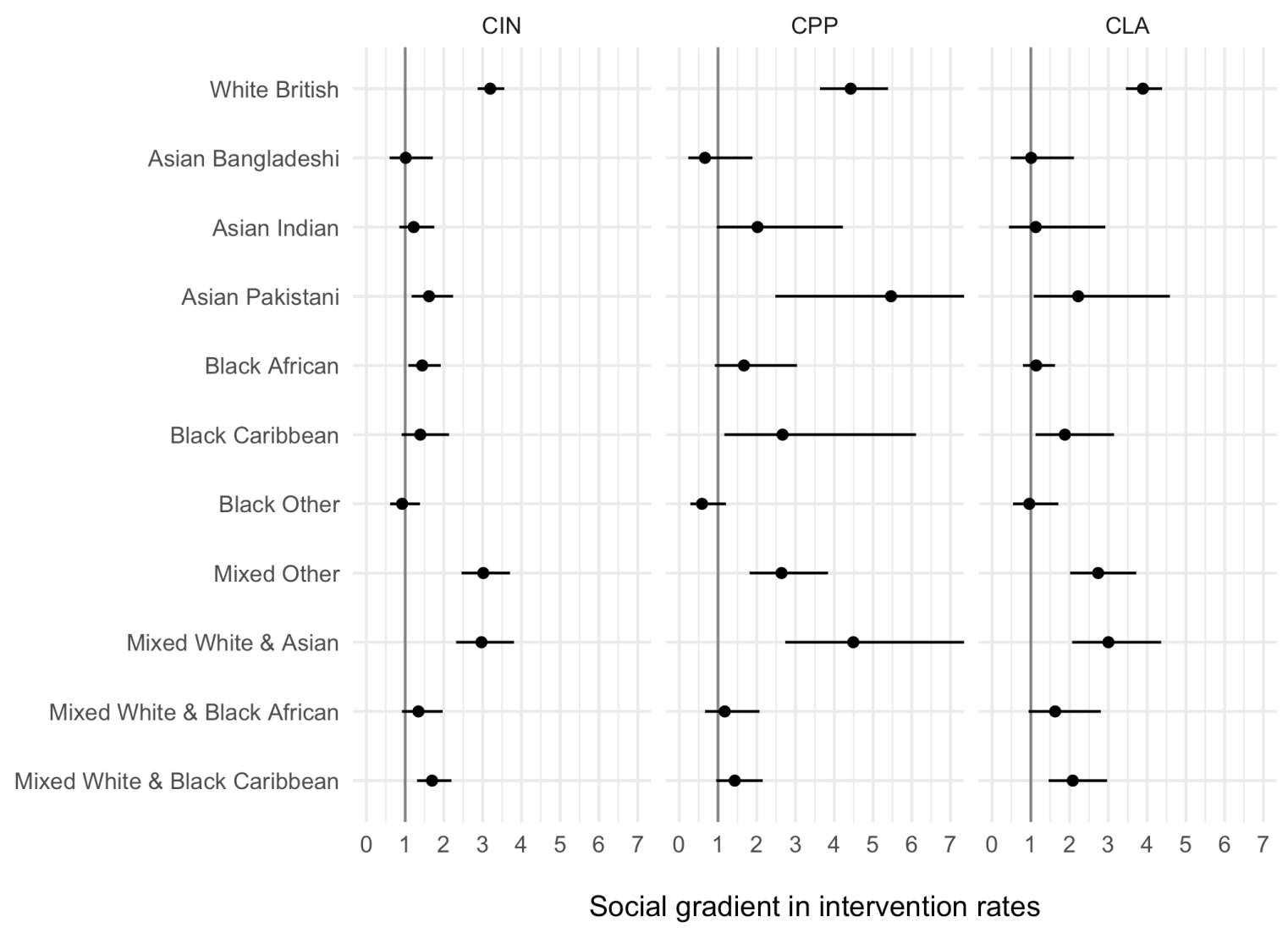

CIN social gradients for ethnic populations other than Mixed Other and Mixed White and Asian populations are significantly lower than the social gradient for White British MSOA populations. In many cases, the social gradient itself is not even statistically significant. CPP social gradients for four of the ethnic group populations are not significantly different to the social gradients in the White British populations, and these four represent disparate ethnic categories. Seven of the ten CPP social gradients are significantly lower. A similar pattern appears in the CLA social gradients, with all but three ethnic populations having significantly lower social gradients. 
The social gradient for White British populations was around 3.2 for $\mathrm{CIN}, 4.4$ for CPP rates, and 3.9 for CLA; this was notably higher than more general estimates of the social gradient in previous research that did not delineate by ethnic population (Webb, et al. 2020). The interpretation of this finding is that for an increase of one standard deviation in MSOA deprivation we would expect the CIN, CPP, and CLA rates within that MSOA to increase by $3.2,4.4$, and 3.9 times, respectively. In other words, increases in deprivation are associated with very large increases in child welfare interventions within MSOAs for White British populations.

Socioeconomic inequalities in child welfare interventions in White British populations can only be described as enormous, with the CLA incidence rate ratio between a high deprivation MSOA and a low deprivation MSOA being 15:1. In other words, for every one child looked after per 10,000 in a low deprivation MSOA we would expect to see 15 children looked after in a high deprivation MSOA. But this is not something exclusive to White British populations. Pakistani and Mixed White \& Asian populations did not have social gradients significantly lower than this. Previous research has also shown that these gradients can be up to five times larger in areas with high income inequality and low overall deprivation than in areas with low income inequality and higher overall deprivation (Webb, et al. 2020).

The only ethnic population to have a social gradient that did not differ significantly from the White British population's in any type of intervention was the Mixed White/Asian population. For Pakistani populations only the CIN social gradient was significantly lower than the White British social gradient, at a 1.6 times increase in CIN rates for each one standard deviation increase in MSOA deprivation, but social gradients for CPP and CLA rates were approximately equal to those for White British populations. The Mixed Other MSOA populations had equivalent CIN social gradients to the White British population, but CPP and CLA social gradients that were significantly lower. Social gradients for the Mixed Other populations were 2.64 and 2.74 for CPP and CLA rates respectively.

In contrast, some ethnic populations had no evidence of a social gradient in intervention rates. For Bangladeshi, Indian, Mixed White and Black African, and Black Other populations the social gradient was not statistically significant for any kind of intervention. This means that we would not expect to see any significant increase or decrease in intervention rates for these ethnic populations when comparing differently deprived MSOAs, all else being equal.

\subsection{Ethnic density and Child Welfare Interventions}

Finally, our models consider the role of ethnic density and the interaction between the ethnicity of a population and the ethnic density of the wider MSOA. Ethnic density of any one particular ethnic group alone was not associated with changes in intervention rates, with the exception of Mixed Heritage ethnic density and Child Protection Plans. Similarly, the interaction between ethnic population and ethnic density was only significant for a few populations' Children in Need rates. 
Untangling Child Welfare Inequalities: Ethnicity, Poverty \& Place

Table 4: Social gradients in MSOA child welfare intervention rates by ethnic population

\begin{tabular}{|c|c|c|c|}
\hline \multicolumn{2}{|c|}{ Children in Need Rate (MSOA Ethnic Population) } & $\begin{array}{l}\text { Significant? } \\
\text { (is there any } \\
\text { social } \\
\text { gradient?) }\end{array}$ & $\begin{array}{l}\text { Is the social } \\
\text { gradient } \\
\text { significantly } \\
\text { different to the } \\
\text { White British } \\
\text { social } \\
\text { gradient? }\end{array}$ \\
\hline Ethnic Group & Social Gradient [95\% Cl] & & \\
\hline White British & $3.19[2.87-3.56]$ & Yes & - \\
\hline Asian Bangladeshi & $1.01[0.60-1.71]$ & No & Yes \\
\hline Asian Indian & $1.22[0.85-1.75]$ & No & Yes \\
\hline Asian Pakistani & $1.61[1.17-2.24]$ & Yes & Yes \\
\hline Black African & $1.44[1.08-1.92]$ & Yes & Yes \\
\hline Black Caribbean & $1.39[0.91-2.13]$ & No & Yes \\
\hline Black Other & $0.92[0.61-1.38]$ & No & Yes \\
\hline Mixed Other & $3.02[2.45-3.70]$ & Yes & No \\
\hline Mixed White \& Asian & $2.97[2.31-3.81]$ & Yes & No \\
\hline Mixed White \& Black African & $1.34[0.91-1.97]$ & No & Yes \\
\hline Mixed White \& Black Caribbean & $1.69[1.31-2.19]$ & Yes & Yes \\
\hline \multicolumn{4}{|c|}{ Children on Child Protection Plans Rate (MSOA Ethnic Population) } \\
\hline Ethnic Group & Social Gradient [95\% Cl] & & \\
\hline White British & $4.42[3.63-5.39]$ & Yes & - \\
\hline Asian Bangladeshi & $0.66[0.23-1.89]$ & No & Yes \\
\hline Asian Indian & $2.02[0.97-4.22]$ & No & No \\
\hline Asian Pakistani & $5.46[2.48-12.04]$ & Yes & No \\
\hline Black African & $1.67[0.92-3.04]$ & No & Yes \\
\hline Black Caribbean & $2.66[1.16-6.11]$ & Yes & No \\
\hline Black Other & $0.59[0.29-1.21]$ & No & Yes \\
\hline Mixed Other & $2.64[1.81-3.84]$ & Yes & No \\
\hline Mixed White \& Asian & $4.49[2.73-7.37]$ & Yes & No \\
\hline Mixed White \& Black African & $1.17[0.66-2.07]$ & No & Yes \\
\hline Mixed White \& Black Caribbean & $1.43[0.95-2.15]$ & No & Yes \\
\hline \multicolumn{4}{|c|}{ Children Looked After Rate (MSOA Ethnic Population) } \\
\hline Ethnic Group & Social Gradient [95\% Cl] & & \\
\hline White British & $3.89[3.45-4.39]$ & Yes & - \\
\hline Asian Bangladeshi & $1.01[0.48-2.11]$ & No & Yes \\
\hline Asian Indian & $1.13[0.43-2.92]$ & No & Yes \\
\hline Asian Pakistani & $2.22[1.08-4.59]$ & Yes & No \\
\hline Black African & $1.14[0.80-1.62]$ & No & Yes \\
\hline Black Caribbean & 1.88 [1.12 - 3.15] & Yes & Yes \\
\hline Black Other & $0.96[0.54-1.71]$ & No & Yes \\
\hline Mixed Other & $2.74[2.01-3.72]$ & Yes & No \\
\hline Mixed White \& Asian & $3.00[2.06-4.36]$ & Yes & No \\
\hline Mixed White \& Black African & $1.63[0.94-2.81]$ & No & Yes \\
\hline Mixed White \& Black Caribbean & $2.08[1.46-2.97]$ & Yes & Yes \\
\hline
\end{tabular}


We hypothesized that intervention rates amongst ethnic minority populations may be higher in instances where ethnic minority populations make up a lower proportion of the overall population. In other words, we were interested in whether greater contact resulted in fewer interventions for ethnic minorities. This does not appear to be the case with regards to ethnic disparities in children's social care. The regression models suggest that, in fact, the only significant relationships were that Black African, Black Caribbean, Black Other and Mixed Heritage Other populations had higher Children in Need rates when the ethnic density of Black and Mixed Heritage ethnic groups respectively was higher - the opposite of what we would expect if the contact hypothesis held true for children and families social work.

An increase of one per cent (these variables were only centred, not standardised, because of non-normal distribution) in the Black African/Caribbean/Other population density of the MSOA population was associated with 1.017, 1.027, and 1.056 times higher rates of CIN for Black African, Black Caribbean, and Other Black populations respectively - a small but significant increase. Similarly, an increase of one per cent in the Mixed Heritage population is associated with a 1.075 times increase in the expected Mixed Heritage Other CIN rates. In other words, in an MSOA with a Mixed Heritage population 1 per cent higher than its neighbour, we would expect $7.5 \%$ higher CIN rates on average. This means that CIN rates for Black African, Caribbean, and some Mixed Heritage ethnic groups are even higher than already identified when the ethnic density of the population is greater than average.

\subsection{Discussion}

There are significant differences in child protection practice between ethnic groups, but these are complex and differ both based on the intensity of child protection intervention and level of deprivation. The relationship between ethnicity and deprivation is substantial and under-researched, particularly for Mixed Heritage (Other) and White and Asian Mixed Heritage populations.

The main take away for any reader of this article should be that there are important gaps in our knowledge of ethnic minority inequities that we cannot simply fill-in with the same explanations we use for the majority population, nor are reductive amalgamations of ethnic groups (particularly Asian ethnic groups) appropriate in practice or analysis. Although structural, socio-economic explanations like the social gradient seem to hold less explanatory power when trying to understand differences in intervention rates in many ethnic minority populations, it is not as simple as saying that the social gradient does not exist for ethnic minority populations. For many group and intervention combinations, it does. It is consistently found in Pakistani, Black Caribbean, Mixed Other and Mixed White/Asian populations when looking at various rates of intervention. Nonetheless, it is absent or lower for most ethnic groups, especially when looking at CIN and CLA rates. We cannot discount that these findings may be the result of limitations in the data, and there is an urgent need to confirm (or revise) these conclusions using individual level data.

The intersection of ethnicity and socioeconomic status 'cuts both ways' (Newitz \& Wray, 1996) in child protection, as it does in other parts of life. Socioeconomic status and the social gradient act as a double-edged sword for some populations: as a protective factor in 
relatively well-off areas, but as a great adversity in deprived areas. This gradient is steepest in White British and Mixed Heritage populations; socio-economic status makes the greatest difference for these children. Meanwhile, for other ethnic populations - Indian, Bangladeshi, and non-Caribbean Black populations - socio-economic status appears to have less bearing on the rates of most child welfare interventions, while ethnicity itself has a large influence.

Mixed Heritage populations - an ethnic group that is poorly defined, forms a growing proportion of the UK population, and about whom we know very little - face the sharp edge of both the social gradient and ethnic inequity. This may be indicative of the particular prejudice associated with underclass narratives faced by working class young mothers of White and Mixed Heritage children that is well documented in sociological literature (Skeggs, 2004; McKenzie, 2013; Kouritzin, 2016); a pervasive cultural narrative from which social work may not have immunised itself against.

We recognise that this paper has only explored one of many possible intersections. Gender, age, ethnicity, disability, sexuality, and class are all important dimensions of experience. We hope this article demonstrates how essential it is to develop intersectional quantitative approaches to derive an accurate view of inequalities in children's services. We also hope that demonstrating this will achieve some change in the routine administrative data collection.

\subsection{Implications for Research, Policy and Practice}

These findings show that models of child protection that are intersectional and see child abuse and neglect within wider structural contexts are not just one approach of many, they are essential for effective anti-racist and anti-poverty practice. A social model of child protection is badly needed: a model which contextualises children's lives and development not only in reference to their acute needs and economic situation but also their identity, one which recognises the impact of the society around the child (Morris, et al., 2018; Featherstone, et al., 2018). To achieve either anti-racist or anti-poverty (or poverty-aware, Krumer-Nevo, 2009, or class-competent, Strier, 2009) social work practice it is necessary to achieve both, because of the intricate relationship between race and class. Models based on adding together disparate structural factors risk misrepresenting the realities of systemic and structural inequalities and achieving neither.

While a simplification, resources such as the tables and figures presented here can act as effective tools for illustrating the differential inequalities at the intersections of ethnicity and socioeconomic status. They highlight the pitfalls of disconnected agendas, especially considering inconsistencies across different forms of intervention. There are no simple, catch-all explanations. Policies to address inequalities in children's social services need to be constructed within an intersectional framework, addressing the unique inequalities each ethnic group faces. The hard work needs to be put in to identify the needs of intersectional populations. Regularising intersectional indicators of ethnic disproportionality, not just indicators of ethnic disproportionality, to evaluate children's services outcomes may serve to direct these services towards greater equity (Tilbury \& Thoburn, 2009). 
Social work practice would also benefit from a more critical engagement with the intersections of whiteness, gender, and class (Jeyasingham, 2012). Do social workers understand the stigma directed towards, and the needs of, White working class mothers in poor neighbourhoods?

Moving research forward may require engagement with the rationale of 'studying up' to better understand intersectional inequalities (Nader, 1972; Gusterson, 1997; Mattsson, 2014). How is capital differently constructed, perceived, and leveraged in the context of child protection? We may find ourselves looking in the wrong places for explanations of ethnic inequity when we focus on the experiences of poor working class ethnic minority families. Indeed, recent research has found that the presence of children's centres in more affluent neighbourhoods flattens the social gradient substantially by increasing rates of intervention in those places (Scourfield, et al. forthcoming). A more fruitful line of inquiry may involve studying how affluent White families utilise economic, social, and cultural capital to avoid surveillance and social work intervention; or why ethnic minority children face greater surveillance in predominantly White schools (Alexander, et al. 2015).

It is important at this stage to restate that there appears to be considerable discrepancies between disproportionality in victim reported abuse in a nationally representative crime survey (Flatley, 2016), and disproportionality in abuse captured by the child protection system in England. Attention needs to be paid to how social work practice might reproduce ethnic inequalities. That is, we must consider variations in the reporting of welfare concerns, and children and families social work responses, as being more than the result of ethnic differences in experiencing child maltreatment. Reporting, assessment, practice, decisionmaking, are not neutral, and all are shaped by structural racism and class prejudice. This leaves us with the perhaps uncomfortable message that we cannot discount an ongoing impact of institutionally racist systems across multiple agencies that anti-racist social work frameworks seek to address; nor can we reject the existence of more complex types of 'institutionalised intersectional injustice' that have yet to be unveiled.

\section{Bibliography}

Alexander, C., Weekes-Bernard, D., \& Arday, J. (2015). The Runymede School Report: Race, education and inequality in Contemporary Britain. London: Runymede.

Allport, G. W. (1954). The nature of prejudice. Cambridge, MA: Perseus Books.

Archer, T. and Stevens, M. (2018) Housing, integration and segregation: A rapid literature review. Retrieved from https://www4.shu.ac.uk/research/cresr/sites/shu.ac.uk/files/housingintegration-segregation-rapid-lit-review.pdf

ATD Fourth World. (N.D.). The Roles We Play: Recognising the Contribution of People in Poverty. Retrieved from atd-uk.org: https://atd-uk.org/wp-content/uploads/2018/07/20141017-TheRoles-We-Play.pdf

Barnard, H., \& Turner, C. (2011). Poverty and ethnicity: A review of evidence. York: Joseph Rowntree Foundation.

Beddoe, L. (2014). Feral families, troubled families: The rise of the underclass in New Zealand 20112013. New Zealand Sociology, 29(3), 51-68.

Bray, R., De Laat, M., Godinot, X., Ugarte, A., \& Walker, R. (2019). The Hidden Dimensions of Poverty. Pierrelaye: International Movement ATD Fourth World.

Brooks, M. E., Kristensen, K., van Benthem, K. J., Magnusson, A., Berg, C. W., Nielsen, A., 
Skaug, H. J., Maechler, M. \& Bolker, B. M. (2017). glmmTMB Balances Speed and Flexibility Among Packages for Zero-inflated Generalized Linear Mixed Modeling. The R Journal, 9(2), 378-400.

Bywaters, P., Brady, G., Bunting, L., Daniel, B., Featherstone, B., Jones, C., Morris, K., Scourfield, J., Sparks, T., Webb, C. (2018a). Inequalities in English child protection practice under austerity: a universal challenge? Child and Family Social Work, 23(1), 53-61.

Bywaters, P., Brady, G., Sparks, T., \& Bos, E. (2014a). Child Welfare Inequalities: New Evidence, Further Questions. Child \& Family Social Work, 21, 369-380.

Bywaters, P., Brady, G., Sparks, T., \& Bos, E. (2014b). Inequalities in Child Welfare Intervention Rates: the Intersection of Deprivation and Identity. Child \& Family Social Work, 1-12.

Bywaters, P., Brady, G., Sparks, T., Bos, E., Bunting, L., Daniel, B., Featherstone, B., Morris, K. Scourfield, J. (2015). Exploring inequities in child welfare and child protection services: Explaining the 'inverse intervention law'. Children and Youth Services Review, 57, 98-105.

Bywaters, P., Bunting, L., Davidson, G., Hanratty, J., Mason, W., McCartan, C., \& Steils, N. (2016). The relationship between poverty, child abuse, and neglect: an evidence review. York: The Joseph Rowntree Foundation.

Bywaters, P., Kwhali, J., Brady, G., Sparks, T., \& Bos, E. (2017). Out of Sight, Out of Mind: Ethnic Inequalities in Child Protection and Out- of-Home Care Intervention Rates. British Journal of Social Work, 47, 1884-1902.

Bywaters, P., Scourfield, J., Jones, C., Sparks, T., Elliot, M., Hooper, J., McCartan, C., Shapira, M., Bunting, L., Daniel, B. (2018b). Child welfare inequalities in the four nations of the UK. Journal of Social Work, 1-23.

Bywaters, P., Scourfield, J., Webb, C., Morris, K., Featherstone, B., Brady, G., Jones, C., Sparks, T. (2019). Paradoxical evidence on ethnic inequities in child welfare: towards a research agenda. Children and Youth Services Review, 96, 145-154.

CACI Ltd. (2019). Paycheck Family Technical Guide. London: CACI Ltd.

Collins, P. H. (2009 [1990]). Towards a politics of empowerment. in Collins, P. H. eds. (2009) Black feminist thought: knowledge, consciousness, and the politics of empowerment (2nd ed.). New York: Routledge.

Carter, D. A. (2009). Jungle Fever: Bold, Beautiful and Unnecessarily Maligned. in Watson, E. (Ed.) (2009). Pimps, Wumps, Studs, Thugs and Gentlemen: Essays on Media Images of Masculinity. 106-126.

Cooper, K., \& Stewart, K. (2013). Does money affect children's outcomes? A systematic review. York: Joseph Rowntree Foundation.

Cooper, K., \& Stewart, K. (2017). Does Money Affect Children's Outcomes? An update. London: Centre for Analysis and Social Exclusion, LSE.

Corley, N. A., \& Young, S. M. (2018). Is Social Work Still Racist? A Content Analysis of Recent Literature. Social Work, 63(4), 317-326.

Coulton, C. J., Crampton, D. S., Irwin, M., Spilsbury, J. C., \& Korbin, J. E. (2007). How neighborhoods influence child maltreatment: A review of the literature and alternative pathways. Child Abuse and Neglect, 31(11-12), 1117-1142.

Cram, F., Gulliver, P., Ota, R., \& Wilson, M. (2015). Understanding overrepresentation of Indigenous children in child welfare data: An application of the Drake risk and bias models. Child Maltreatment, 20: 170-82.

Crenshaw, K. (1989). Demarginalizing the intersection of race and sex: a Black feminist critique of antidiscrimination doctrine, feminist theory and antiracist politics. University of Chicago Legal Forum: 139-168.

Crossley, S. (2018). Troublemakers: The Construction of 'Troubled Families' as a Social Problem. Bristol: Policy Press.

Dalmage, H. (2000). Tripping on the Color Line: Black-white Multiracial Families in a Racially Divided World. New Brunswick, NJ: Rutgers University Press. 
Department for Communities and Local Government. (2015, Sept 30). English indices of deprivation 2015. Retrieved Mar 17, 2016, from Gov.uk:

https://www.gov.uk/government/statistics/english-indices-of-deprivation-2015

Dominelli, L. (2017). Anti-Racist Social Work. London: Macmillan.

Drake, B., Lee, S. M., Jonsen-Reid, M. (2009). Race and child maltreatment reporting: Are Blacks overrepresented? Children \& Youth Services Review. 31(3): 309-316.

Eaton, G. (23 ${ }^{\text {rd }}$ April 2010). Labour and Tory posters spoof Little Britain. New Statesman.

Eddo-Lodge, R. (2017). Why I'm no longer talking to white people about race. London: Bloomsbury.

Equality and Human Rights Commission. (2018). Article 14: Protection from discrimination.

Retrieved from https://www.equalityhumanrights.com/en/human-rights-act/article-14-

protection-discrimination (12 ${ }^{\text {th }}$ June 2020).

Featherstone, B., Gupta, A., Morris, K., \& White, S. (2018). Protecting Children: A social model. Bristol: Policy Press.

Flatley, J. (2016) Abuse during childhood: Findings from the Crime Survey for England and Wales, year ending March 2016. Office for National Statistics:

https://www.ons.gov.uk/peoplepopulationandcommunity/crimeandjustice/articles/abusedu ringchildhood/findingsfromtheyearendingmarch2016crimesurveyforenglandandwales\#perso nal-and-household-characteristics-of-survivors-of-abuse-during-childhood [Accessed 27 February 2020].

Gibson, M. (2016). Social worker shame: A scoping review. British Journal of Social Work, 46, 549565.

Gulliver, K. (2016) Forty Years of Struggle. London: Human City Institute.

Gupta, A. (2015). Poverty and shame - messages for social work. Critical and Radical Social Work, 3(1), 131-139.

Gusterson, H. (1997). Studying up revisited. PoLAR: Political and Legal Anthropology Review, 20(1), 114-119.

Harman, V. (2010). Social Work Practice and Lone White Mothers of Mixed-parentage Children. British Journal of Social Work, 40: 391-406.

Harris, M. S. (2014). Racial Disproportionality in Child Welfare. New York: Columbia University Press.

Hastings, A. (2009). Poor Neighbourhoods and Poor Services: Evidence on the 'Rationing' of Environmental Service Provision to Deprived Neighbourhoods. Urban Studies, 46(13), 29072927.

Haylett, C. (2001). Illegitimate subjects? Abject whites, neo-liberal modernisation and middle class multiculturalism. Environment and Planning D: Society and Space, 19(3), 351370

Herman, M. R., Campbell, M. E. (2012). I wouldn't, but you can: Attitudes toward interracial relationships. Social Science Research, 41(2), 343-358.

Jensen, T. (2014). Welfare Commonsense, Poverty Porn and Doxosophy. Sociological Research Online, 19(3), 277-283.

Jeyasingham, D. (2012). White Noise: A critical evaluation of social work education's engagement with Whiteness studies. British Journal of Social Work, 42(4), 669-686.

Jones, O. (2011) Chavs: The Demonisation of the Working Class. New York: Verso Books.

Katz, I. (1996). The Construction of Racial Identity in Children of Mixed Parentage: Mixed Metaphors. Philadelphia, PA: Jessica Kingsley Pubs.

Keddell, E. \& Davie, G. (2018). Inequalities and Child Protection System Contact in Aotearoa New Zealand: Developing a conceptual framework and research agenda. Social Sciences, 7(89), 1-14.

Kim, H., \& Drake, B. (2018). Child maltreatment risk as a function of poverty and race/ethnicity in the USA. International Journal of Epidemiology, 47(3), 780-787.

Kouritzin, S. G. (2016) Mothering across colour lines: decisions and dilemmas of white birth 
Untangling Child Welfare Inequalities: Ethnicity, Poverty \& Place

mothers of mixed-race children, Journal of Multilingual and Multicultural Development, $37: 8,735-747$

Krumer-Nevo, M., Monnickendam, M., \& Weiss-Gal, I. (2009). Poverty-Aware Social Work Practice: A conceptual framework for social work education. Journal of Social Work Education, 45(2), 225-243.

Kwan, S., \& Spiers, K. (Eds.) 2004. Mixing it up: Multiracial Subjects. Austin: University of Texas Press.

Mattsson, T. (2014) Intersectionality as a Useful Tool: Anti-Oppressive Social Work and Critical Reflection. Affilia, 29(1), 8-17.

McGarvey, D. (2017) Poverty Safari: Understanding the Anger of Britain's Underclass. Edinburgh: Luath Press.

McKenzie, L. (2013). Narratives from a Nottingham council estate: a story of white workingclass mothers with mixed-race children. Ethnic \& Racial Studies, 36(8), 1342-1358

McKenzie, L. (2015). Getting By: Estates, class, and culture in Austerity Britain. Bristol: Policy Press.

Nayak, S. \& Robbins, R. (2018). Intersectionality in Social Work: Activism and practice in context. London: Routledge.

Lavalette, M., \& Penketh, L. (2013). Race, Racism and Social Work: Contemporary issues and debates. Bristol: Policy Press.

Lavergne, C., Dufour, S., Trocmé, N., \& Larrivée, M. C. (2008). Visible minority, Aboriginal, and Caucasian children investigated by Canadian protective services. Child welfare, 87(2).

de Leeuw, E. D. and Hox, J. (2008). Missing Data. Encyclopedia of Survey Research Methods. Retrieved from http://sage-ereference.com/survey/Article_n298.html

Lenth, R. (2019). emmeans: Estimated Marginal Means, aka Least-Squares Means. R package version 1.4.3.01.

Maguire-Jack, K., Lanier, P., Johnson-Motoyama, M., Welch, H., \& Dineen, M. (2015, September). Geographic variation in racial disparities in child maltreatment: The influence ofcounty poverty and population density. Child Abuse and Neglect, 0-13.

Mason, W., \& Bywaters, P. (2016). Poverty, Child Abuse and Neglect: Patterns of Cost and Spending. Families, Relationships \& Societies, 5(1), 155-161.

Menrotra, G. (2010). Toward a Continuum of Intersectionality Theorizing for Feminist Social Work Scholarship. Affilia, 25(4): 417-430.

Morris, K., Mason, W., Bywaters, P., Featherstone, B., Daniel, B., Brady, G., ... Webb, C. (2018). Social work, poverty, and child welfare interventions. Child and Family Social Work, 23(3), 364-372.

Nader, L. (1972). Up the anthropologist: perspectives gained from studying up.

Newitz, A. \& Wray, M. (1996). What is "White Trash"?: Stereotypes and Economic Conditions of Poor Whites in the U.S. Minnesota Review, 47, 57-72

Office for National Statistics. (2019, May 24). Population estimates for Lower layer super output areas (LSOA) in England and Wales, single year of age and sex, mid-2001 to mid-2017. Retrieved from ons.gov.uk: https://www.ons.gov.uk/peoplepopulationandcommunity/populationandmigration/populat ionestimates/adhocs/009983populationestimatesforlowerlayersuperoutputareaslsoainengla ndandwalessingleyearofageandsexmid2001tomid2017

Office for National Statistics (2016) Ethnic group, national identity and religion. Retrieved from ons.gov.uk:

https://www.ons.gov.uk/methodology/classificationsandstandards/measuringequality/ethni cgroupnationalidentityandreligion

O'Hara, M. (2020). The Shame Game: Overturning the Toxic Poverty Narrative. Brisol: Policy Press.

Olumide, G. 2002. Raiding the Gene Pool: The Social Construction of Mixed Race. London: 
Pluto Press.

Owen, C., \& Statham, J. (2009). Disproportionality in Child Welfare. London: University of London.

Pelton, L. H. (2015). The continuing role of material factors in child maltreatment and placement. Child Abuse and Neglect, 41, 30-39.

Platt, L. (2007). Poverty and Ethnicity in the UK. Bristol: Policy Press / JRF.

Platt, L. (2019). Understanding inequalities: Stratification and difference. Hoboken, NJ: John Wiley \& Sons.

Putnam-Hornstein, E., Needell, B., King, M., \& Johnson-Motoyama, M. (2013). Racial and ethnic disparities: A population-based examination of risk factors for involvement with child protective services. Child Abuse and Neglect, 37, 33-46.

Robson, K., \& Pevalin, D. (2015). Multilevel Modeling in Plain Language. London: Sage.

Scourfield, J., Webb, C., Elliott, M., Staniland, L., \& Bywaters, P. (forthcoming). Are child welfare intervention rates higher or lower in areas targeted for enhanced early years services? Child Abuse Review.

Skeggs , B. (2004). Class Self and Culture, London: Routledge

Strier, R. (2009). Class-competent social work: a preliminary definition. International Journal of Social Welfare, 18: 237-242.

Stubblefield, A. 'Beyond the Pale': Tainted Whiteness, Cognitive Disability, and Eugenic Sterilization. Hypatia, 22(2), 162-182.

Threadgold, S. (2015). 'Struggle street' is poverty porn with an extra dose of class racism. Australia Opinions. 80: 34-35.

Tilbury, C. (2009). The over-representation of indigenous children in the Australian child welfare system. International Journal of Social Welfare, 18(1), 57-64.

Tilbury, C. \& Thoburn, J. (2009). Using racial disproportionality and disparity indicators to measure child welfare outcomes. Children \& Youth Services Review, 31(10): 1101-1106.

Tyler, I. (2008) "Chav Mum Chav Scum": Class disgust in contemporary Britain. Feminist Media Studies, 8(1), 17-34

Tabachnick, B. G., \& Fidell, L. S. (2014). Using Multivariate Statistics. Harlow: Pearson.

Welshman, J. (2006). Underclass: A History of the Excluded 1880-2000, London: Hambledon Continuum.

Walker, R. (2014). The Shame of Poverty. Oxford: Oxford University Press.

Webb, C., Bywaters, P., Scourfield, J., McCartan, C. Bunting, L., Davidson, G., Morris, K. (2020) Untangling child welfare inequalities and the 'Inverse Intervention Law' in England. Children \& Youth Services Review. https://doi.org/10.1016/j.childyouth.2020.104849

Winders, J. (2003) White in all the wrong places: white rural poverty in the postbellum US South. Cultural Geographies, 10, 45-63.

Wray, M. (2006). Not Quite White: White Trash and the Boundaries of Whiteness. Durham, NC: Duke University Press. 